\title{
A sustainable urban regeneration project to protect biodiversity
}

\author{
Elvira Tarsitano ${ }^{1,2}$ (D) Alba Giannoccaro Rosa ${ }^{3} \cdot$ Cecilia Posca $^{3} \cdot$ Giovanni Petruzzi $^{3} \cdot$ Michele Mundo $^{3} \cdot$ \\ Marcello Colao ${ }^{2}$
}

Accepted: 7 December 2020 / Published online: 30 December 2020

(C) The Author(s) 2021

\begin{abstract}
The sustainable urban redevelopment project to protect biodiversity was developed to regenerate the external spaces of an ancient rural farmhouse, Villa Framarino, in the regional Natural Park of Lama Balice, a shallow erosive furrow (lama) rich in biodiversity, between two suburbs of the city of Bari (Apulia, Italy) and close to the city airport. This work includes a complex system of activities aimed not only at a spatial revaluation, necessary to relaunch the urban image, but it is accompanied by interventions of a cultural, social, economic, environmental and landscape nature, aimed at increasing the quality of life, in compliance with the principles of sustainability and social participation. One of the means to revitalize a territory subject to redevelopment is the planning of events and activities of socio-cultural value that involve the population to revive the sense of belonging to the territory and the community and at the same time to protect the biodiversity of the urban park of the protected natural area.
\end{abstract}

Keywords Biodiversity $\cdot$ Urban regeneration $\cdot$ Sustainability $\cdot$ Urban ecology

\section{Introduction}

In recent years in Europe there has been a constant proliferation of initiatives from below that have seen the active and operational participation of heterogeneous subjects (citizens, professionals and territorial animators) at stake as true agents of sustainable territorial development. Urban areas often represent very critical territorial entities characterized with a high concentration of human activities impacting on urban ecosystems. This underlines the importance of considering the urban environment in an ecosystem way, in order to highlight the traits related to material and energy flows, to resources natural cycles as well as biotic and abiotic components of substrate for living beings. Therefore, the urban ecosystem could be analyzed through its parts as ecological factors, starting from the idea of the urban ecology as instrument of knowledge of physical spaces and urban functional cycles, in other words, evaluating both the abiotic (biotope) and the biotic (biocenosis) parts, considering the urban abiotic parts integrated with urban

Elvira Tarsitano

elvira.tarsitano@uniba.it

1 Sustainability Center, University of Bari Aldo Moro, Piazza Cesare Battisti, Bari, Italy

2 Abap-APS, Bari, Italy

3 Cooperativa Sociale Tracceverdi, Bari, Italy life processes for the conservation of biodiversity (Tarsitano et al. 2017). The issues on the active protection of the territory and on the quality of life in general are registering an increasing importance in the decision-making processes not only of economic but also social and cultural development and this is demonstrated by the fact that among all the eleven main objectives of the signed Partnership Agreement from Italy for the use of European structural and investment funds, six are focused on sustainability and the environment. In addition, the Ipbes evaluation reports with the edition of the four reports on the state of biodiversity, the result of more than three years of work, written by 550 experts from over 100 different countries, are based on answers to key questions for each of the four regions (Americas, Africa, Asia-Pacific and EuropeCentral Asia), including: why biodiversity is important; where we are making progress; what are the main threats and opportunities for biodiversity; how we can adapt policies and institutions for a more sustainable future. The report examines the role for human well-being that biodiversity and ecosystem services can assume, evaluating the opportunities to manage production and consumption in a sustainable way also through ecological infrastructures and technologies (Ipbes 2018). In addition to the commitment signed in 2015 to achieve the 17 goals of the agenda 2030; just think of the goal 15: To protect, restore and promote sustainable use of Earth's ecosystem, sustainably manage the forests, combating desertification, stop and roll back land degradation, and stop the loss of biological diversity (UNDESA 2015). Indeed, "the next decade 
will be devoted to the restoration of ecosystems". This was established by the United Nations Assembly last March, underlining the urgent need to take actions dedicated to the protection of biodiversity for the period between 2021 and 2030. A decade dedicated to environmental protection and biodiversity protection: there are two billion hectares of degraded land to be recovered, a unique opportunity for local and global work and development. For example, in the document "Zero draft of the post-2020 global biodiversity framework", prepared by the Working group 2020 (Wg2020), authority of the Convention on ecological diversity, it is proposed that by 2030 the $30 \%$ of ecosystems will be protected, raising the rod for those areas rich in biodiversity. The goal is to provide guiding principles for defining national strategies to halt the loss of biodiversity, thus protecting ecosystems and ecosystem services. The Convention signatory countries are now thinking about how to offer the whole world a strategy that from 2020 to 2050 aims to make us "Living in harmony with nature" (Convention on Biological Diversity 2020). The earth is a value and the care of its elements is the fulcrum on which to build the future of an area and its inhabitants and at the same time be a way to achieve the objectives of the agenda 2030 (Tarsitano et al. 2019). Urban parks have very specific tasks established by law, but if they are located in complex and difficult contexts and realities, they cannot avoid confronting the needs of the territory, even if these, apparently, are beyond their institutional purposes. Among the purposes of a protected natural area, the social aspects and, in general, those related to health and physical and psychophysical well-being are not always adequately valued. The achievement of well-being, in the broadest sense of the term, is a desire that characterizes the era in which we are living, where the need to dedicate quality time to ourselves is increasingly felt. Here then, a protected natural area can represent an effective means of achieving this result. The rediscovery of contact with nature and with the rhythms of the agricultural world, if thought and managed with passion and competence, can truly work miracles, in addition to contributing actively to safeguarding the territory and biodiversity by facilitating responsible and aware access to the places, they have allowed those same places classified as marginal and residual to find a centrality through an unprecedented sensitivity, proposing a system of cultural and social values linked to rurality and natural resources. In particular, the urban structure of the city of Bari (Apulia region, Italy) is set up with a centralization of buildings in the central areas (historic center and Murat quarter) which becomes less dense along the administrative borders of the city and it is precisely within this margin that there are degradation and abandonment of community spaces. The metropolitan area of Bari has developed within a system of "furrows" widespread in the central part of the Apulian territory (southern Italy), called "lame" or temporary / occasional water bodies that carry masses of water from the area of Alta
Murgia to the sea (Fig. 1). These waterways have always been anthropized since places naturally predisposed to the development of human activities and therefore arise punctual elements widespread throughout the water basin of the province of Bari (Apulia Regional Territorial Landscape Plan - PPTR. Landscape areas, 2015; Strategic Plan BA2015 of the Metropolitan area of Bari 2015). However, many of the buildings built within these areas remained detached from the development dynamics of the city, remaining on the margins both from a geographical, administrative and socio-cultural point of view. Villa Framarino and the Regional Natural Park of Lama Balice are located at the internal area of this territorial framework: the need for a territorial redevelopment has therefore been highlighted, which foresees the redefinition of the role of the building and of the green areas within the development dynamics of the Metropolitan area widespread throughout the water basin of the province of Bari (Fig. 2) (The Strategic Plan BA2015 of the Metropolitan area of Bari 2015; PUG - General Urban Plan - Municipality of Bari. Preliminary Programmatic Document 2014). The parts of cities subject to redevelopment interventions are therefore subject to a series of improvements that make them compatible from an environmental point of view, with the use of ecological materials, as autonomous as possible from an energy system point of view, able to limit water and electricity consumption, spaces for social, cultural and religious aggregation, in order to obtain an overall increase in the quality of life of the inhabitants and protect urban biodiversity (The Apulia Regional Territorial Landscape Plan - PPTR 2015; The Strategic Plan BA2015 of the Metropolitan area of Bari 2015; PUG - General Urban Plan - Municipality of Bari. Preliminary Planning Document 2014). The Park needs to consolidates its own organization systematizing cultural, scientific, social and associative resources present in the territory which are the heart of this project as well as its technical and infrastructural equipment (Ferraro and Hanauer 2014; Veech 2003; Raimondi et al. 2013; Tarsitano et al. 2017). The aims to enhance and promote the Natural Parks and the Protected Areas of the regions involved. In this case, the area undergoing redevelopment is represented by the areas of Villa Framarino, potential green spaces to be actively lived. The characteristics of geomorphologic and landscape importance of the area as well as margins within the urban context of the city of Bari are the main elements of this redevelopment. The redevelopment intervention carried out in the relevant areas of Villa Framarino, inside the Lama Balice Park, helps to reinforce and restore, where there are no ecological connections, in order to rebalance and mitigate any environmental imbalances caused on the environment by human activities. In addition, it contributes to maintain the anthropic elements that characterize the agricultural landscape and with a high ecological and landscape value, such as the dry stone walls that enclose parts of the projected areas. A peculiarity of the 


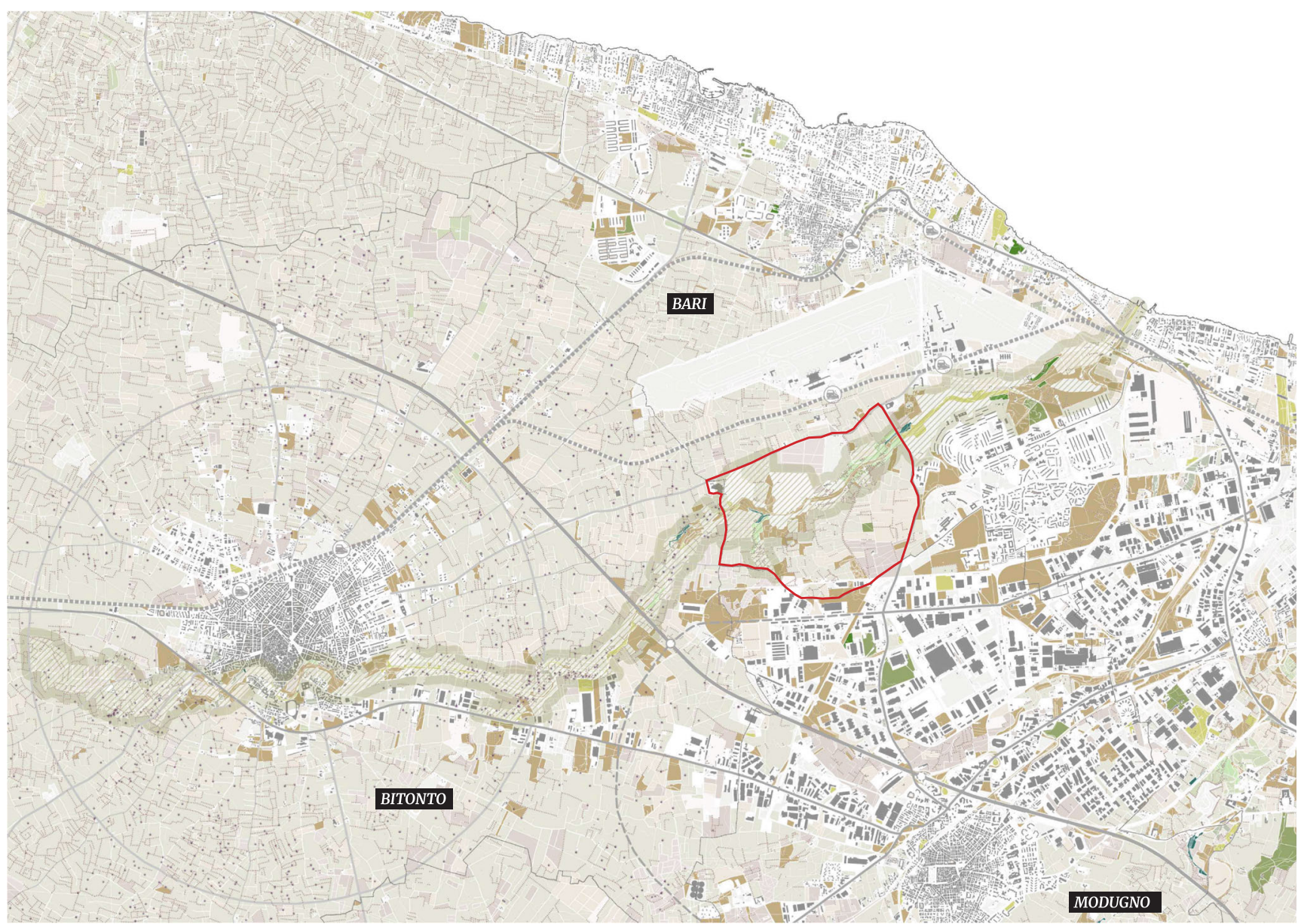

Fig. 1 The perimeter of the park Lama Balice. Lama Balice is a park characterized by a Mediterranean, thermophilic and xerophilic vegetation. The microhabitat and the natural vegetation combined to the

Apulian landscape (Apulia Region, Italy) is the dense network of dry limestone walls present both in the countryside and close to the blades, which in addition to the historical, cultural and social value, represent a sort of reservoir, "atmospheric steam condensers" able to capture the water by condensation during the sunny diurnal hours and return it to the ground during night-time cooling and at dawn until saturation and then available to the root systems of the plants that grow nearby (Fig. 3) (Tarsitano et al. 2017). Lama Balice is a park characterized by a Mediterranean, thermophilic and xerophilic vegetation. The microhabitat and the natural vegetation combined to the presence of agro-ecosystems offers a stabile environmental worthiness deserving of protection and conservation. The purpose of the project was through the story of a good practice experience, to be promoters of the theme of sustainable urban regeneration and social innovation in a protected natural area in order to become a reference for other realities. The project objectives are the construction of elements of the ecological network of connection between rural territory and urban presence of agro-ecosystems offer a stabile environmental worthiness. Lama Balice presents an elevate biodiversity about the fauna

ecosystem through the pursuit of low impact agricultural practices; the promotion of cultivars that improve the biodiversity values of agro-ecosystems; the regeneration of environmental resources, water, soil, air, to compensate for the urban impact; the promotion of hospitable environments for flora and fauna; the creation of public spaces and services. The park is projected as a supporting element of the reinforcement of the urban space, the equipment and services provided are compatible with the rural character of the area such as social gardens, sports equipment and public spaces of connection and entrance to the park; the park is also an opportunity to promote different mobility, creating a slow network within the park (Territorial Plan of the Natural Regional Park of Lama Balice - Strategic Plan Document 2016). In line with the new European programming, which generally reinforces the place-based approach and integrated urban development in the project, acting simultaneously cross-cutting policy areas such as human capital, social inclusion, innovation, the environment, landscape, agriculture, biodiversity 


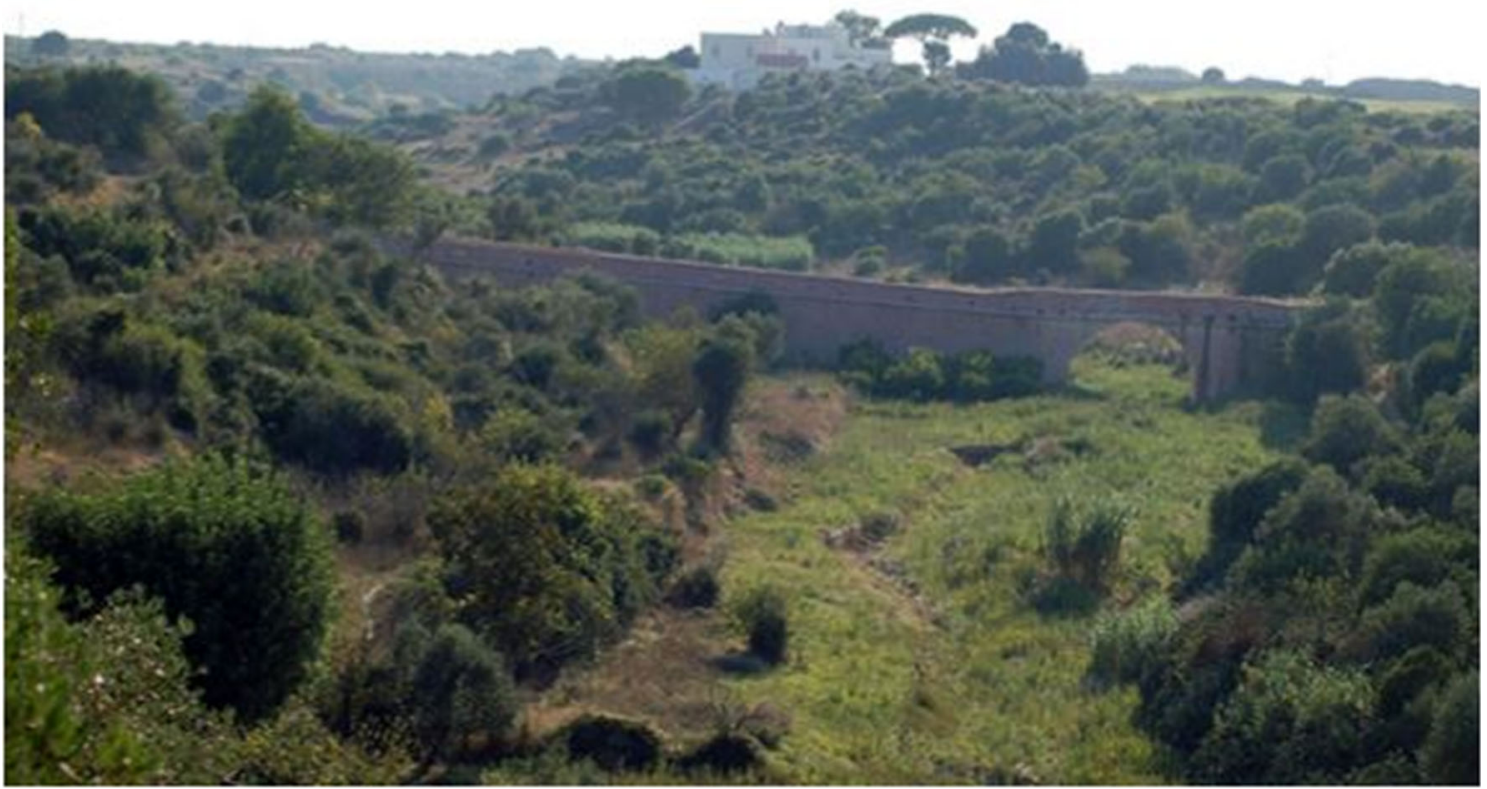

Fig. 2 Villa Framarino. All the Lama Balice basin is characterized by medieval country-houses, churches and Masserie (typical Apulian farms). Villa Framarino is situated inside the lama, it is an ancient farm built up in the Middle Age and recently restored, it has become the

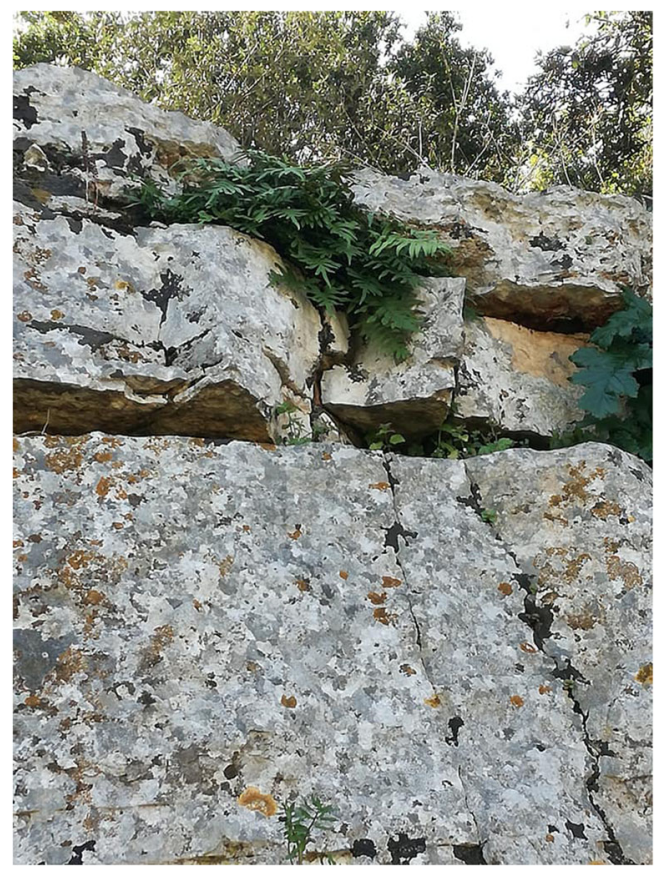

Fig. 3 Dry stone walls. Constant elements over the centuries in Lama Balice are dry walls: they were realized with calcareous rocks in order to delimit an estate or to separate the wood from the pasture-land, the sown field from the orchard. A particular Apulian landscape is the dense dry stone walls (limestone) network typifying the countryside around the lama and besides the historical, cultural and social value, becomes a kind of tank, "atmospheric steam condensers", able to collect water from the condensation in the hot daylight hours and return it to the ground during the night cooling and dawn until saturation, and then later make that water available to root systems of plants growing around headquarter and the core of the main activities in the Park. The Villa Framarino, located on the left side of the lama Balice, falls in an area rich in traces of the past. Near the Villa there are several paths parallel to the medieval street Via Traiana

conservation and sustainability. With regard to these aspects, starting from the Park's planning process, the aim will be to systematize a series of actions aimed at conserving biodiversity and the ecosystem; conserve and reorganize agricultural areas; recovering degraded and abandoned areas; improve the interaction between environmental systems and human settlements; improve accessibility and usability; promote knowledge of the territory and landscape.

\section{Methods}

\section{Study site}

The Lama Balice Urban Park is a protected area of about 500 ha in the middle of the Metropolitan City of Bari. The land became natural reserve on March 24, 1980. Later, in 1997, it was re-included in the list of the regional protected areas, it became Regional Natural Park thanks to the Regional Act on 05 June, 2007. The area goes from Bari to Bitonto and the regional Park takes its name from the so called lama (a karstic split) and it represents one of the largest ecological corridor in the Metropolitan City of Bari, with its $37 \mathrm{~km}$ of length (from the Murgia plateau to the sea) and forms the bed of an ancient stream, called Tiflis with a mainly linear path (Fig. 1) (Tarsitano et al. 2017). Despite the considerable anthropic pressure, interesting habitats can still be found in the Lama, such as a scrub-forest of olive trees, lentisk and hawthorn on the north side, a holm oak wood on the south side, 
several rocky areas, some of which were once used as limestone quarries, and a marshy area with reeds near the sea (Mastropasqua 2013).

\section{Development of a method for monitoring biodiversity in the park}

This project, in addition to the priority theme of sustainable urban regeneration, also had the aim of experimenting with a method for monitoring biological diversity by addressing two aspects in particular: the wealth of species and the complexity of habitats. Two lines of work have been identified to develop the two aspects of biodiversity. An analysis of the environmental units was carried out and a detailed list of all possible environmental components that contribute to achieving biological diversity, present in the park, was prepared. Each element was clearly defined so that this list could be used as a standardized tool, without the possibility of misunderstandings during field surveys (Sinibaldi et al. 2017). To measure the function of the different units of the landscape, a subdivision was made into: point-like elements, expressed in simple numbers; linear, whose length was measured; planar, whose surface was measured. The identification and measurement of ecosystem units took place through direct field observations; then the percentage occupied by each element within the park of Lama Balice was calculated. The Shannon-Wiener (H) biodiversity index was chosen to express the diversity of environmental units. For the analysis of specific diversity, an inventory of all the species present in an area is an impossible task even within a metropolitan park of limited size, due to lack of time and resources. Therefore, the choice of taxa was guided by the fact that each group selected, being known and appreciated by citizens, had a sure impact on public opinion. Over the three years (2016-2018) of the "A park to live" project, the subject of this work, prospections were carried out on five sample areas described in Table 1. With the application of this method it is possible to describe biodiversity within an urban park in an objective, standardized and repeatable way. It can therefore be used as a tool to monitor the wealth of habitats and species within a regeneration and conservation project also due to the size of the area subject to intervention.

\section{The regeneration project}

The protection and enhancement are implemented with different technical methods, which, starting from the knowledge of the state of biodiversity and the factors that can threaten it, concern, for example, the in situ and ex situ conservation of plant and animal species, the defense and the restoration of the habitats in which the species carry out their biological cycle, the maintenance and creation of an appropriate ecological connectivity between the various environments and finally the fight against genetic erosion. These interventions, in addition to qualifying the area of intervention in a landscape way, contribute to ensuring the shelter of many animal species. For the naturalization and vegetative restoration, reintegration, control and restoration interventions of the vegetation cover are foreseen; the goal is oriented conservation, consolidation, management of production uses with environmental compatibility criteria, in relation to both the vegetation content of the territory and the characteristics of the sites. In particular, the safeguard interventions concern:

Table 1 Habitat description

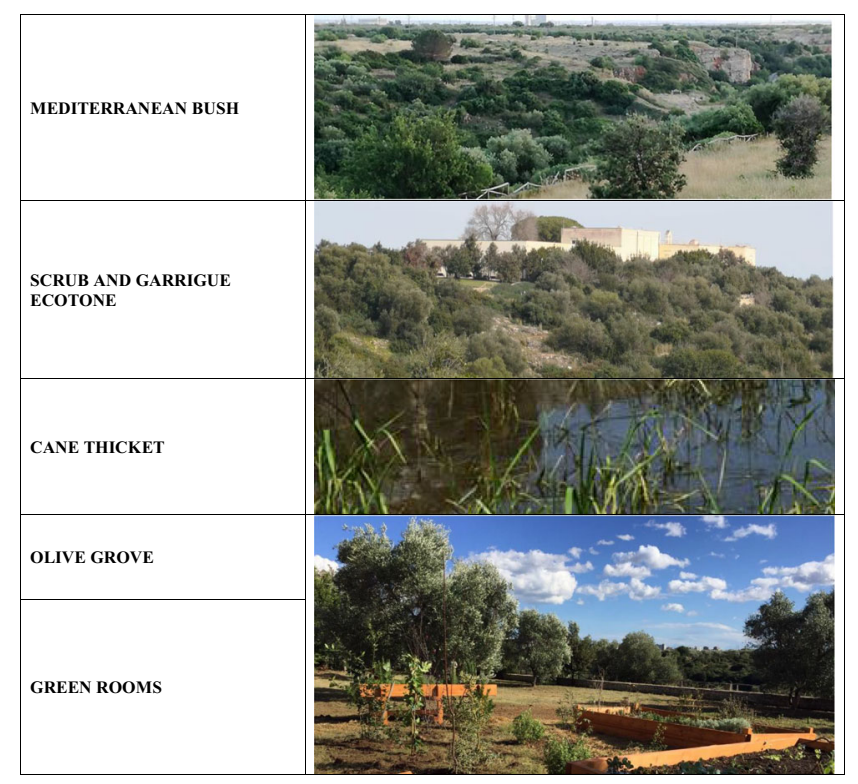


conservation and consolidation of the vegetation cover of the soils, in particular of the xero-thermophilic grasslands; integration and restoration of the autochthonous vegetation cover, restoration of ecological connections of the hygrophilous vegetation; recovery of the natural landscape; planting of tree and shrub vegetation; the maintenance of vegetation; restoration of wooded areas. About that, five "green rooms" have been created, that is, open-air areas whose vegetative elements, the natural materials used and their location can offer functional and educationalcurative ideas: "the sensory labyrinth", "the room of colors", "Barefooting", "butterfly garden", "organic and synergistic vegetable garden" and installations. These spaces are located within the areas of Villa Framarino in such a way as to define real routes to be visited in a sector-specific approach. The redevelopment project also provides for the ordinary and extraordinary maintenance of the entire area of the park also through light pruning, cleaning, correct management of the existing greenery and, where necessary, the application of eco-compatible vegetation protection methods to protection of biodiversity. The maintenance of the irrigation system has become necessary for the care and protection of existing vegetation, as well as to allow the planted essences to successfully overcome the stress period due to transplanting. The dry stone walls that enclose the areas belonging to Villa Framarino have also been redone and rearranged, where damaged. The works were carried out in full compliance with current environmental laws, with the aim of "promoting environmental education, training and scientific research activities, as well as sustainable recreational activities, in particular through the use of civic buildings in these ends recovered (Fig. 4) (Regional Law N.15 of 5/06/2007 'Establishment the Regional Natural Park of Lama Balice; Territorial Thematic Urban Plan for Landscape - PUTT / p. of Apulia 2014; Apulia Regional Territorial Landscape Plan - PPTR 2015; Giannoccaro et al. 2017; AA.VV. Società Cooperativa Sociale Tracceverdi 2017).

\section{The sensory labyrinth}

It begins with "the sensory labyrinth", a walk inside the Mediterranean scrub species present on site, in the area identified with "sclerophyll vegetation area" on the land use map of the Regional Territorial Landscape Plan (PPTR) and outside on the border of the Park area. It is a re-thickening, in some points, of the already existing tree species in order to create narrow paths between rows of tall shrubs and vegetative tracts impenetrable to the view, but which by touch and smell

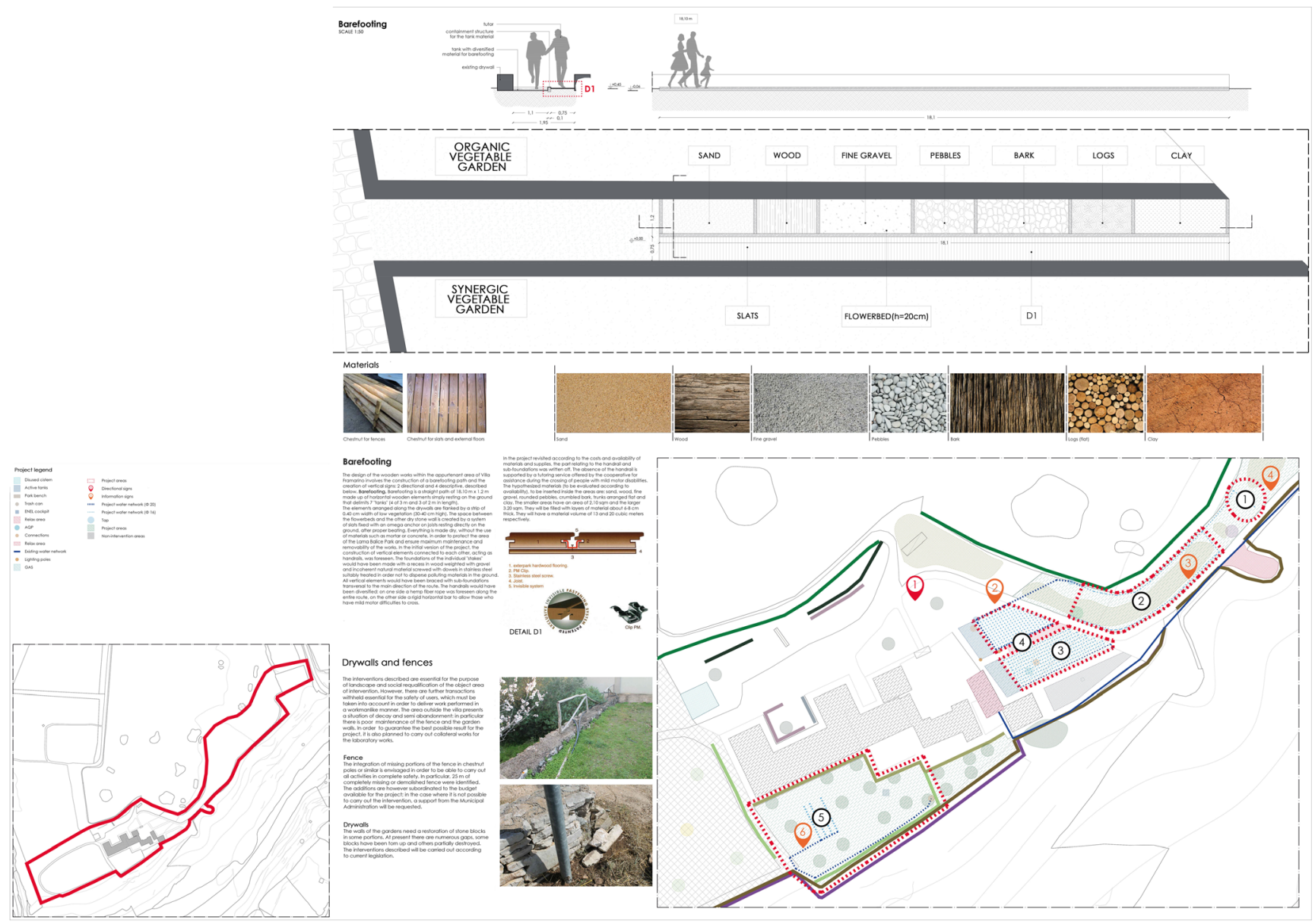

Fig. 4 Map of the regeneration project. Designs by the architechs R. Giannoccaro and dr. M. Mundo 
are discovered by users, invited to follow it. The re-thickening works directly on the vegetative fragmentation of the Mediterranean scrub bordering the park and which overlooks the riverbed and optimizes the anthropogenic impact close to the park, increasing the "green barrier" against noise. This allows to restore the vegetable connection, so as to allow the animal species directly connected to these vegetative species to increase in number and variety. This has a positive effect especially on lepidoptera and on the whole trophic chain dependent on them. The essences chosen to thicken some traits are: Rhamnus alaternus and / or Laurus nobilis and / or Fillirea and / or Pistacia lentiscus. The number of plants planted was about 50 plants. The path to be done within the Mediterranean scrub of about $127 \mathrm{~m}$ is defined by local limestone placed at the end in a random way in order to "draw" the path on the ground, respect a precise distance and stem the anthropic impact on the surrounding vegetative mass (Fig. 5).

\section{The color room}

Still in the area outside the perimeter of the Park, the labyrinth leads to the "room of colors", a circular area that contains a resting and meeting area for users, defined by different Mediterranean shrub and herbaceous species, of seasonal flowering and with different colors: ranging from warm tones (yellow, orange, red) to cold tones (lilac, purple, blue, white). "The color room" is an area of about 59 square meters, whose hedges of medium and medium-high shrubs, planted at a distance of $70 \mathrm{~cm}$ and arranged in such a way as to draw a circle, delimit the space. There are two rows of hedges that downgrade in height inwards, of different species and characters, in order to make the room green colored all year round. The vegetative essences chosen are Mediterranean and protect the characteristics of the host place (Fig. 5).

\section{Barefooting}

The "barefooting", sensory path to be walked by bare feet, is located between the two areas used as a vegetable garden (biological and synergic), that is, on the right side of Villa Framarino. The path on the ground is formed by areas $(1 \mathrm{~m} \times 1.5 \mathrm{~m})$ delimited by wooden rods and hosting different natural materials (smooth stones, bark, sand, fine gravel, foliage, wood / trunks). The material used rests directly on the

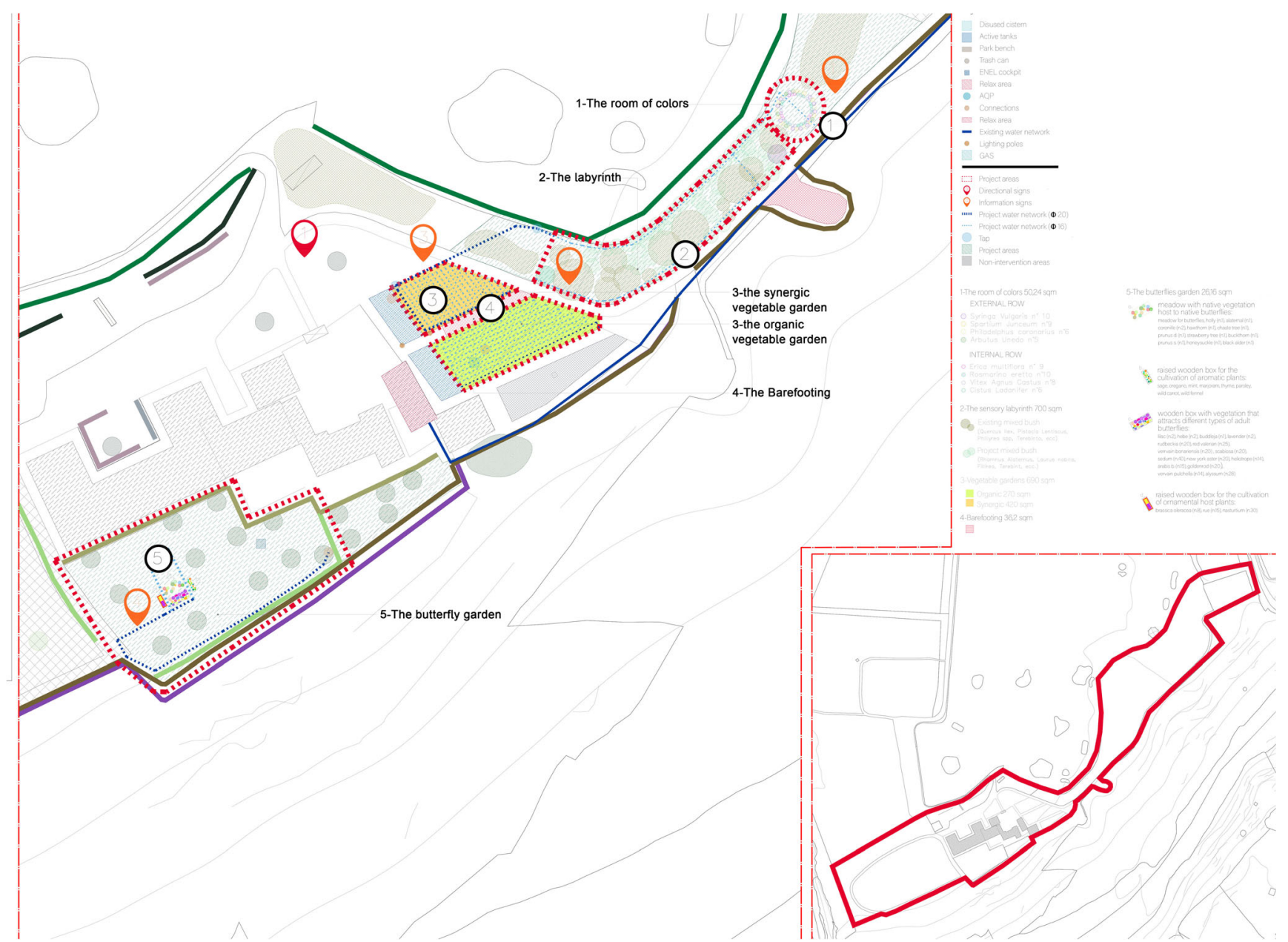

Fig. 5 Map of the sensory labyrinth and the color room. Designs by the architechs R. Giannoccaro and M. Mundo 
ground in such a way that it can be removed if necessary, in full respect of the soil and the surrounding landscape. These natural materials stimulate the sense of touch through the contact that is established with the bare feet of users who walk along the path. Parallel to the tanks containing different natural material, there is a wooden platform useful for guides and tutors of users with reduced mobility or little autonomous movements. This platform is raised from the ground through parallel running beams that allow ventilation to prevent the rotting of the wood used. The wood used is outdoor pine specially treated to resist atmospheric agents (Figs. 4 and 6).

\section{The butterfly garden}

The "butterfly garden", on the other hand, is located on the back of Villa Framarino, among the olive trees, an area that the Land Use map of the Apulia Region mistakenly identifies as a "sports area". This garden has the purpose of attracting the butterflies present on the territory, through smells and colors. As for the other areas, the butterfly garden is not an invasive garden and respects the habitat and root systems of the already existing specimens. The impact of transplanting herbaceous species is minimal, as it was carried out with simple manual tools. The butterfly garden has a fundamental ecological function since it enhances the ecological infrastructure present in the Park in favor of lepidoptera, pollinating insects and auxiliaries in general. This is because there is the presence of nourishing species for insect larvae and plants with inflorescences

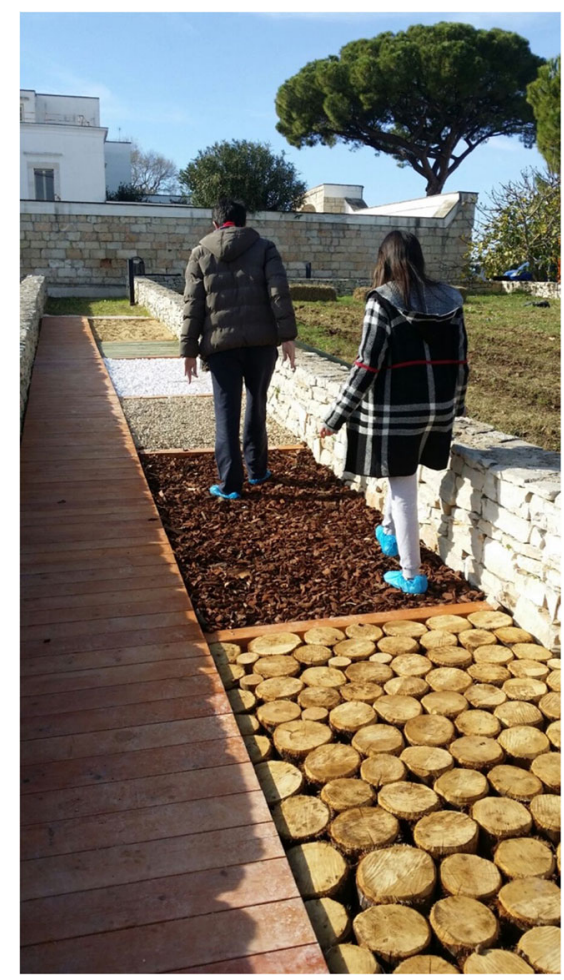

Fig. 6 Barefooting with a strong banner function. The latter support the adults of insects with their rich production of nectar and pollen. The garden is designed to house groups of users (Figs. 5 and 7).

\section{The vegetable gardens}

The area used for vegetable gardens has been located to the right of Villa Framarino, incorrectly defined as a sports area by the Land Use map of the Apulia Region. This area is internal to the border of the park and is made up of three areas delimited by dry stone walls and routes that are currently not very usable due to uncultivated greenery. One of the three areas, the smallest, houses technical wells for the existing irrigation system. The organic and synergic vegetable gardens were therefore placed in the other two areas, respectively measuring $270 \mathrm{~m}^{2}$ and $420 \mathrm{~m}^{2}$. The agricultural products of the organic garden were obtained from methods and techniques that exclude the use of fertilizers and plant protection products deriving from synthetic chemistry, thus fully respecting the principles of organic agriculture. In the synergistic garden, methods were used that positive synergies between the different species of plants, both spontaneous and cultivated, as well as the methods and techniques envisaged for organic agriculture increase. In both cases, the presence of auxiliaries, insects useful for crops, such as natural predators and pollinators, was favored. To obtain the two types of vegetable garden, it was necessary to carry out preliminary cultivation operations. In particular, we proceeded to a weeding with a cutter bar of the invasive weeds of the two areas. Subsequently, the areas underwent a tillage aimed at turning over the slices of soil so as to release the intrinsic fertility possessed by land that was never cultivated. Simultaneously with these operations, further organic and nitrogenous substance was added in the form of mature manure. Only afterwards was it possible to transplant the vegetable species. This use has also made it possible to maintain the area which, due to its location, has a fundamental role in the aesthetics of the municipal complex (Figs. 4 and 8).

\section{The wooden installations and natural architectures}

The redevelopment project of a green space inside a protected natural area cannot be separated from the importance of promoting the usability of the property in question also through the installation of signs suitable for the environmental and landscape context as well as functional to the Park users. Both vertical directional signs and punctual information signs have been provided. The first is fundamental for the immediate identification of the location of the areas of performance of the activities and the understanding of the same activities. A vertical directional element was designed and built positioned at the entrance of Villa Framarino (Fig. 9). The detailed signage of the activities has a panel structure similar to that 
Fig. 7 The butterfly garden. Is composed by: - an area ( $4.5 \mathrm{~m}$ * $2 \mathrm{~m}$ ) where only native plants have been planted (in full respect of the existing one) that can attract butterflies already present and sighted in Lama Balice Park; - a wooden tank,removable if necessary, $(4.5 \mathrm{~m} * 2 \mathrm{~m})$ hosts plants because they are highly attractive for butterflies and caterpillars among the most beautiful in this existing habitat; two raised wooden basins for vegetable gardens $(1.20 \mathrm{~m} * 3 \mathrm{~m})$, removable if necessary, which hosts herbaceous plants useful for feeding caterpillars

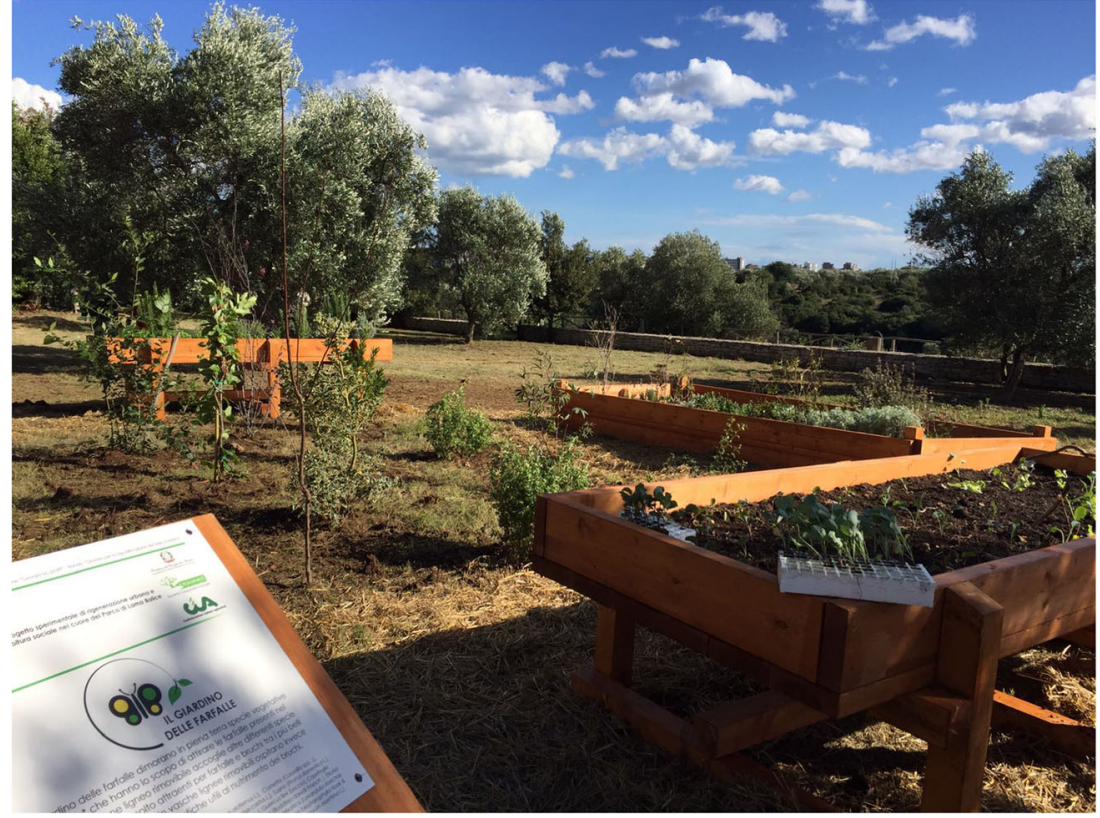

previously described in photo 6 , but smaller $(1.15 \times 0.08 \mathrm{~m})$ with the addition of an oblique panel that functions as a lectern and on which it is applied a descriptive panel $(60 \times 60 \mathrm{~cm}-$ inclined by $30^{\circ}$ ) with the name of the green room and a brief description of it. Here too, the Braille translation characterizes the signage, making it accessible even to the blind. This signage is easy to remove as it is simply placed on the ground. With the project "A Park to live", Lama Balice Natural Park has been equipped with an important tool to allow $360^{\circ}$ use, even for people with mobility and / or physical problems. The installation for birdwatching creates a real location to catch migratory birds and has been located close to the ridge, in a somewhat protected and easy to mitigate area (Fig. 10). Even this natural element, with zero environmental impact, is easy to remove: it is, in fact, simply placed on the ground. Lastly, $\mathrm{n}$ - 4 sensory didactic panels have been designed Always in pine wood treated for outdoor use, these panels complete the didactic and sensory offer through the creation of: $n{ }^{\circ} 1$ sensory panel made up of wooden tiles inlaid with figures of fingerprints plants and animals of the typical flora and fauna of Lama Balice; $n^{\circ} 1$ sensory panel with revolving cube divided into 4 open compartments where to place natural elements (leaves, branches, stones, soil, etc.), $\mathrm{n}{ }^{\circ} 1$ Pan flute with Arundo donax reeds, $\mathrm{n}{ }^{\circ} 1$ panel composed of a recreational labyrinth where some typical fauna of Lama Balice and its habitat. These

Fig. 8 The organic and synergic vegetable gardens

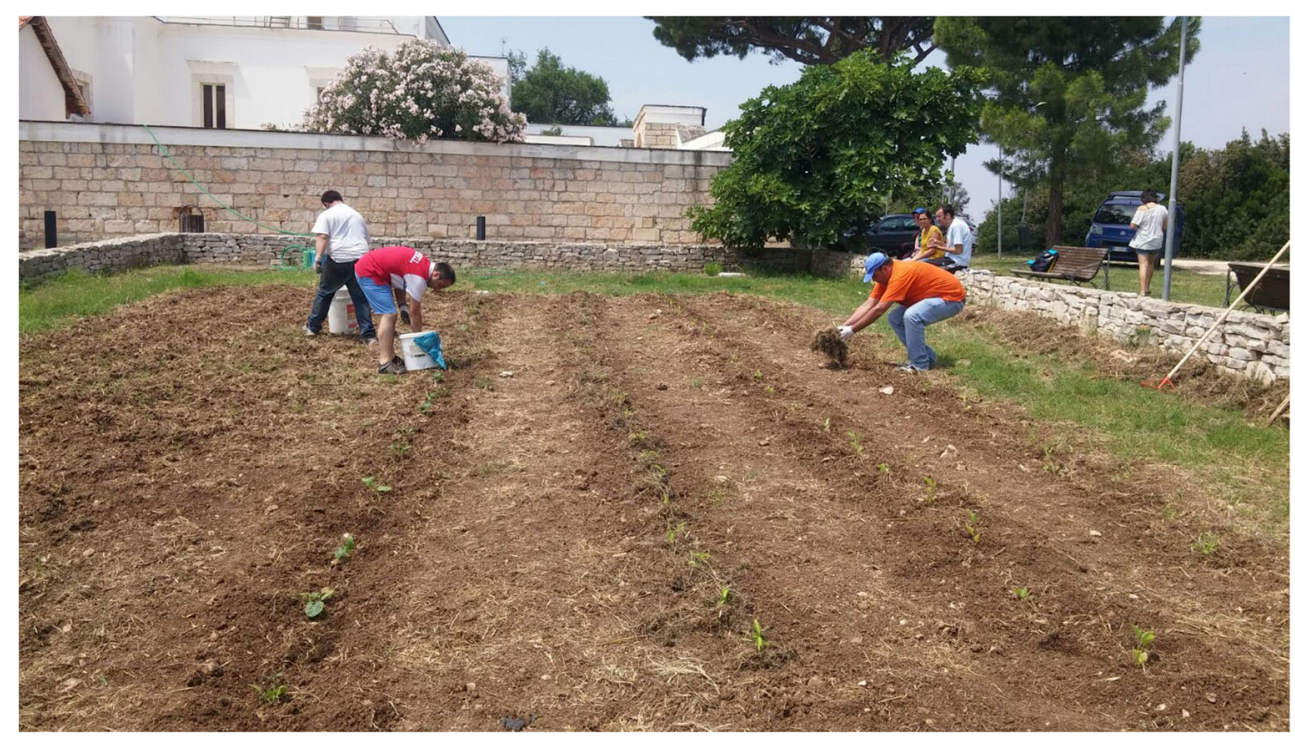




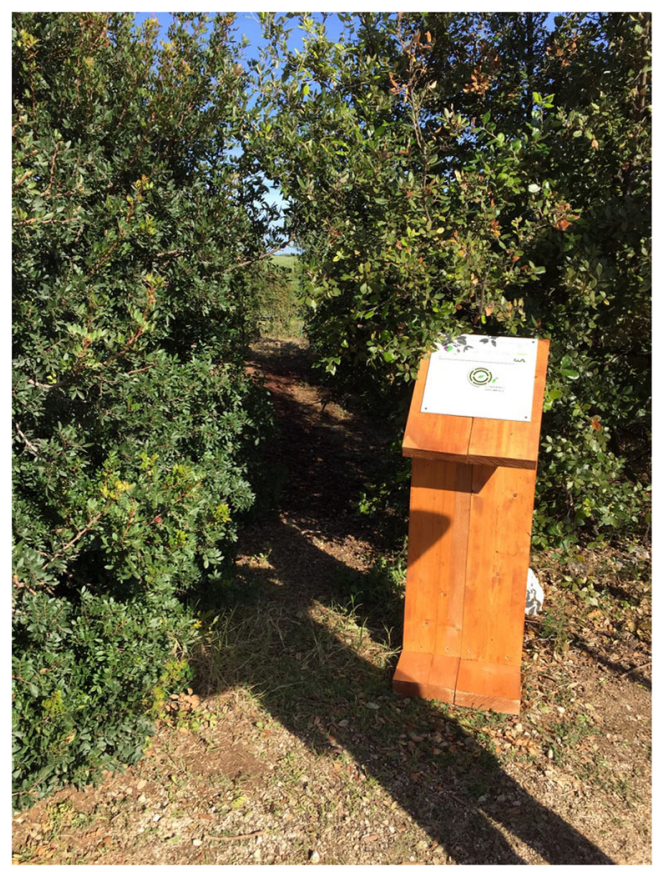

Fig. 9 The wooden installations a wooden structure consisting of an element $(2.15 * 0.08 \mathrm{~m})$, including hardware and poles to be driven into the ground for a minimum depth and suitably anchored to the panel to avoid creating the sail effect due to the action of the wind and any other horizontal component acting on the panel. To this end, the pile is founded with a system of wooden foundations, fine and coarse gravel, sand. Forex panels ( 5 slabs of $0.1 * 0.40 * 0.02 \mathrm{~m}$ ) have been applied to the supporting structure, hooked to the structure, which direct the visitor towards the "green rooms" designed for Villa Framarino. A tactile map with Braille translation completes the georeferencing information indicating the exact point where you are with respect to Villa Framarino building and the green rooms with respect to this entry point

installations are large enough to be used by children and adults. They are removable elements, resting on the ground through a base which filled with ornamental stones and / or soil can act as an ornamental planter.

\section{The interventions and techniques used to protect biodiversity}

The redevelopment project involved reinforcing the ecological infrastructure in the areas belonging to Villa Framarino. The ecological connections, in particular the floristic ones, were depleted of human intervention, often harmful and clumsy. The depletion of the plant connections was aggravated by the absence of maintenance and supervision for the protection and enhancement of the area. The maintenance of the relevant areas, therefore, was one of the most important and decisive interventions in the realization of the redevelopment and revitalization project. The already existing specimens of holm oak, laurel, olive, phyllirea and mastic have undergone light pruning operations, so as to limit their excessive vigor making the foliage more balanced and to eliminate the diseased parts attacked by insects, as in the case of several specimens of holm oak (Quercus ilex). The latter were very debilitated and with different parts of the hair dying: intervention with mineral oils, environmentally friendly products and usable in organic agriculture was therefore necessary. All plant protection interventions were carried out with products that can be used in organic agriculture. These interventions were accompanied by interventions of weeding of weeds which have become intrusive and of cleaning up areas of various types of debris and waste. The arrangement and integration of the existing irrigation system was decisive for the success of the redevelopment and regeneration project. All the designed green thematic areas, with the exception of the "barefooting"
Fig. 10 Birdwatching, natural installation made with plant elements characterizing the surrounding environment: wood and arundo donax. Design by LAN (Natural Architecture Laboratory)

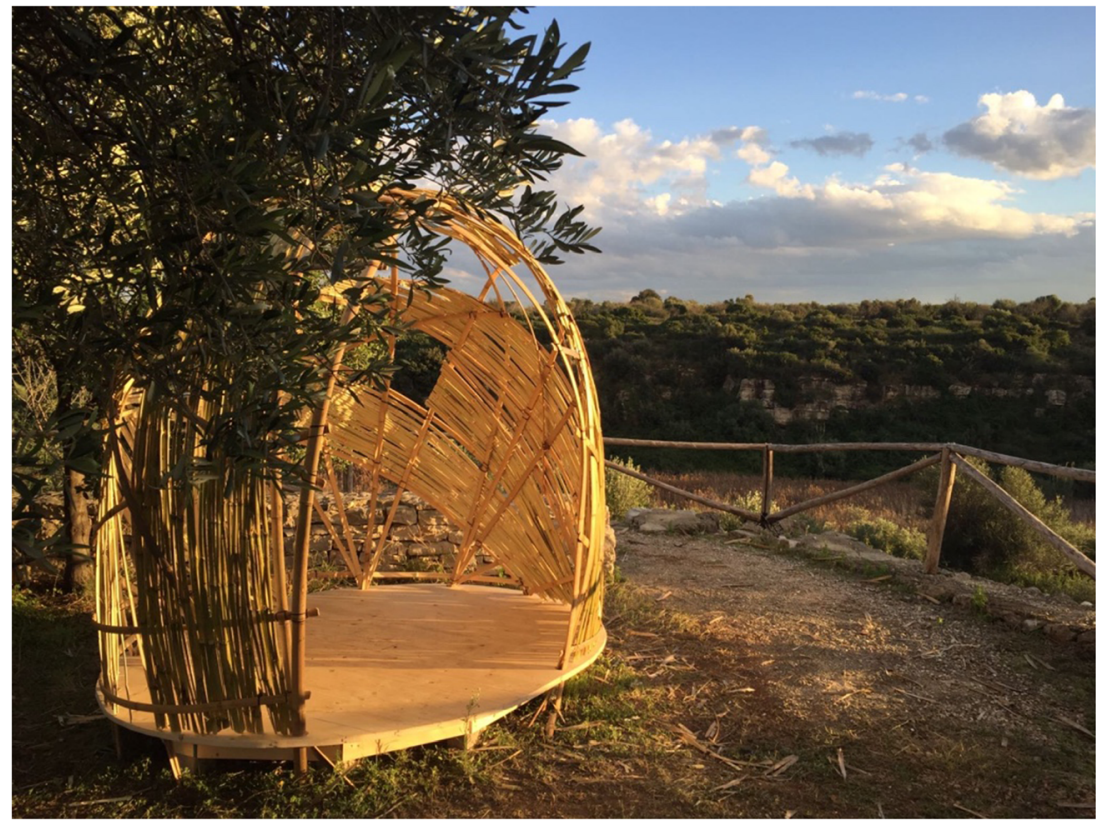


area, have been equipped with pipes with self-compensating drips. Irrigation has become necessary to allow the plants planted to overcome the dry summer period, but also the different periods of scarce rainfall that have followed during the colder seasons. Furthermore, irrigation has become necessary for the shrub and tree plants planted during the project in order to overcome transplant stress, a period in which the root system is less functional, because it is compromised during transplant operations: the water supply was integrated with irrigation, even in humid months. In the "sensory labyrinth" there is an area with sclerophyll vegetation. The intervention aims to redefine the green area with the same tree vegetation so as to enhance the distance through the bushes. The species used for the thickening are typical species of the Mediterranean scrub and in addition to those already mentioned, strawberry tree (Arbutus unedo) and laurel (Laurus nobilis) have been transplanted. The transplants took place by digging a hole slightly larger than the container that contained the root ball of the plants, respecting the specific habitat of the specimens already present. In addition, the equipment used for planting shrub specimens has been minimally invasive on pre-existing root systems. Emergency irrigation was carried out immediately after the transplant, in order to minimize the water stress of the roots. The specimens already present in the area, very vigorous, were pruned slightly respecting their specific habitat as much as possible. Some specimens of laurel were replaced during the course of the project, as they had root systems damaged by wild boars, numerous presence in the park. In the "color room", species with showy inflorescences, but always of Mediterranean origin, have been transplanted, without departing from the essences present in the park. The meeting function for users of the park is accentuated by the scalar blooms of the transplanted species that we find inside. Also in this area the transplanting of the specimens was done respecting the specific habitat of the specimens already present. In addition, the equipment used for the planting of shrub specimens is minimally invasive of the existing root systems. The excavation carried out does not differ much from the diameter corresponding to that of the containers containing the earthen bread of the shrubs. The specimens of transplanted shrubs and bushes are distinguished by the different flowering periods. The flowers of these species have inflorescences with an important banner function. They are very attractive for pollinating insects, in particular for apoid hymenoptera, hoverflies and lepidoptera. Some of these species, such as cistus, are also nurturers of some lepidoptera larvae present in the park. Being species typical of the Mediterranean scrub, they perform a function of refuge for auxiliary insects, organisms useful in biological control. This characteristic applies to all the species transplanted in the various pertinent areas. The choice of species is one of the fundamental elements of the project aimed primarily at maintaining and restoring the biological balance that is disturbed by the anthropogenic pressure to which the park is subjected.

The "vegetable gardens" were designed with the aim of making a small area of the park more productive. The two areas have been subjected to a superficial working with a motor cultivator to make the soil ready for the transplanting of the seedlings and for the sowing. Two types of vegetable gardens have been created, managed differently: one through the principles of synergistic agriculture, the other through the principles of organic agriculture. In both cases, the crops were managed without the aid of synthetic products. The cultivation followed seasonality, in summer cucurbits and the inevitable turnip greens. Leguminous crops were sown as catch crops during the spring. The soil of the vegetable gardens was rich in organic matter, as it was never cultivated, but also rich in spontaneous herbaceous vegetation that competed with the crops. The fortnightly users themselves carried out the manual scrapping of the ground, with the help of tools such as hoes and rakes. In the green area called the "butterfly garden", species attracting and feeding the butterflies have been planted.

The different indigenous species have been transplanted to the ground, respecting the root systems of olive trees and laurels present around the transplanting area. In addition, three boxes were placed, two raised, one at ground level, to facilitate the planned laboratory activities. The boxes were made of wooden material and provided with holes for draining excess water, both irrigation and meteoric. Once the holes had been made, the boxes were lined with plastic sheeting so that the roots could not damage the structures. In one of the raised boxes, plants such as lettuce and chicory have been sown. These provide nourishment to the larvae that hatch from the eggs that adults lay on these plants. The larvae then feed and develop at the expense of these species and pupa. From the pupa, often contained in a cocoon, the following season a butterfly emerges which will feed on the nectar present on the attractive species transplanting into the other boxes.

Officinal species such as rosemary, thyme, oregano, mint and savory were transplanted into the other raised bed. These species are very attractive for lepidoptera and in general for all useful insects. The main function of useful insects, such as lepidoptera, is the pollination of plant species that are attractive to them. In the absence of pollination, many plant species cannot reproduce. From an ecological point of view, this area is the most important, as it allows the enhancement of the park's ecological infrastructure and connects the various habitats (Figs. 4 and 5).

\section{The biodiversity of the park}

Lama Balice represents a real "ecological corridor" characterized by plant species connected to animal species, thus presenting a rich biodiversity. According the vegetation, the lama 
is characterized by a complex mosaic of plant communities, with particular regard for the variety and heterogeneity of the semi-natural herbaceous formations. In fact, more than 400 species of vascular plants are known for the area of Lama Balice Park. Most of these, however, are linked to the reduced surfaces of the rocky slopes where there are semi-natural formations of scrub and grassland. The main plant species present in the park are summarized in Table 2 (Sinibaldi et al. 2017). The wide environmental and vegetation heterogeneity of Lama Balice favors the diversification of ecological niches and the simultaneous presence of a considerable animal diversity, especially if compared with the relative uniformity of the surrounding area. Furthermore, the permanence of water, even only for short periods, represents an exceptional resource in an environmental context strongly influenced by karst. The cognitive picture of the animal biodiversity of the Park is somewhat fragmented, however it may have information collected during recent studies and thanks to the contribution of the network of citizens always present for the protection and enhancement of the Park. The main animal species present in the park are summarized in Table 3 (Sinibaldi et al. 2017). Among mammals, the presence of some carnivores is documented. Particular attention should be paid to the recent appearance of wild boar (Sus scrofa), a species that is expanding rapidly in Apulian area. Signs of the presence of wild boars from the Murgia area can now be observed in almost the entire course of the lama. Although no detailed studies on the chiropterofaune of the Park are known, it is important to underline the value of the cave and hypogean environments of Lama Balice for the conservation of this group of mammals, particularly sensitive to changes of anthropic origin and subject to protection measures pursuant to the Habitat Directive (Tarsitano et al. 2017). In the Park there are more than 40 species of nesting birds (Ferrara 2017), a high number compared to neighboring anthropized contexts. Much richer and more diversified, exceeding 130 species, the number of species that use the Park's environments during migratory stops and in the wintering period results. The presence of numerous species of waterfowl, which is concentrated in the winter and pass period, is closely linked to the presence of temporarily flooded areas, both along the coast and in the innermost sections of the lama (Ferrara 2017). Among the most representative groups, ducks, herons, slugs and numerous waders. Several other species protected by the Birds Directive are found as migrants or winterers in the Park. Studies carried out under the "Action plan for the conservation and management of amphibians and reptiles and Lama Balice Regional Natural Park and Regional Nature Reserve Oriented Lakes of Conversano and Gravina di Monsignore", promoted by the Apulia Region, Municipality of Conversano, Municipality of Bari and the Municipality of Bitonto, highlight the peculiarities of the Lama Balice herpetofauna (Mastropasqua 2013). In particular, the seasonal pools that recreate on the bottom of the
ex-INES seem to represent an important reproductive site for the emerald toad. With the exception of the common gecko, grass snake and green frog, the species of reptiles and amphibians mentioned require specific conservation measures according to the Habitats Directive. Recent observations, on the other hand, make it possible to ascertain the presence of at least 31 species of Lopidoptera Ropaloceri (butterflies) in the Park area (Cagnetta et al. 2019), a large number when compared with the specific wealth of the adjacent territories. The conservation of some of these species is also linked to the presence of particular plant species and habitats (Table 1).

\section{Discussions and conclusions}

The considerations discussed so far should be carefully considered and assessed from an ecosystem approach to planning urban areas, placing the emphasis on the enhancement of the territorial heritage in all its components: environmental, urban, cultural and social, trying to contrast the process of " deterritorialization "(Tarsitano 2003). The ecosystem approach allows to consider the territory in co-evolutionary terms as a historical result deriving from the interactions between human settlements and the environment, between nature and culture with a view to sustainable development of the territories, which allows the achievement of the objectives of the 2030 agenda (Dobson 2007; UNDESA 2015). In particular, the achievement of objective 15 , life on earth, precisely allows the protection, restoration and favors a sustainable use of terrestrial ecosystems, including urban ecosystems, to contrast desertification phenomena, stop and reverse the degradation of the soil, and stop the loss of biological diversity (Asvis 2018, 2019). Therefore, ecological criteria of protection and planning should allow the fusion of the city with the landscape, also through the identification of valid indicators of urban sustainability and indicators of ecological fragmentation in spatial planning, such as: areas of biodiversity and naturalness (the city is structured as a mosaic of habitats); emergency indices and relationship between the use of renewable energies in the urban area; population / recycling / restoration ratio indices; material cycle indices; introduction of the ecological footprint parameter, as a constraint to urban planning (McCool and Stankey 2004; Tarsitano 2006). The strengthening of territorial identities, the reconstruction of the co-evolutionary relationships interrupted between human settlement and the environment favors the recovery a lasting and sustainable balance between human settlement and the natural environment as well as counteracting environmental and social degradation. Specifically, considering in this case the area subject to intervention, the role played by the system of blades (erosive furrows), which insist on the entire Apulian territory, for the rebalancing of urban ecosystems in terms of sustainable development for the achievement of the objectives 


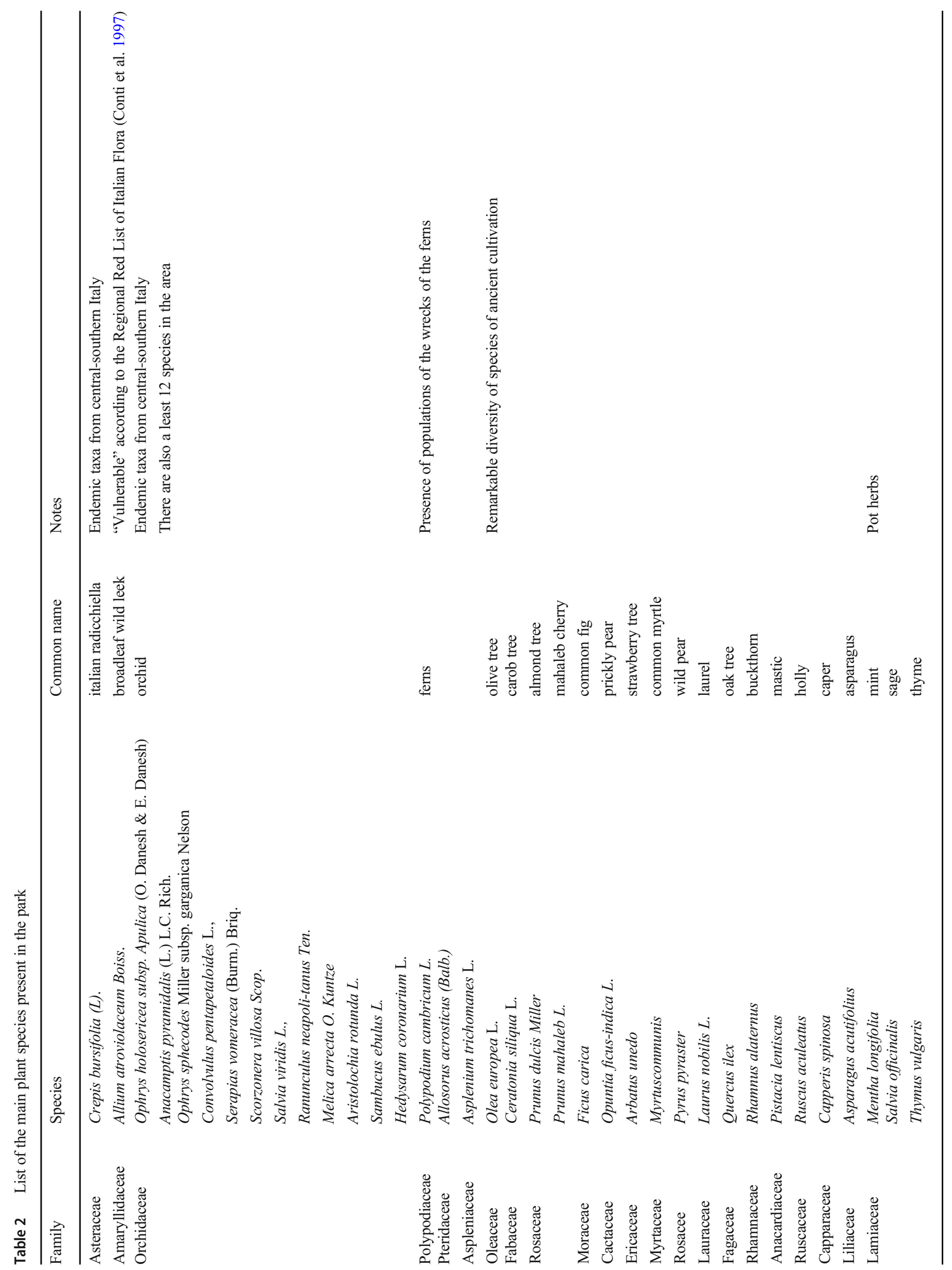




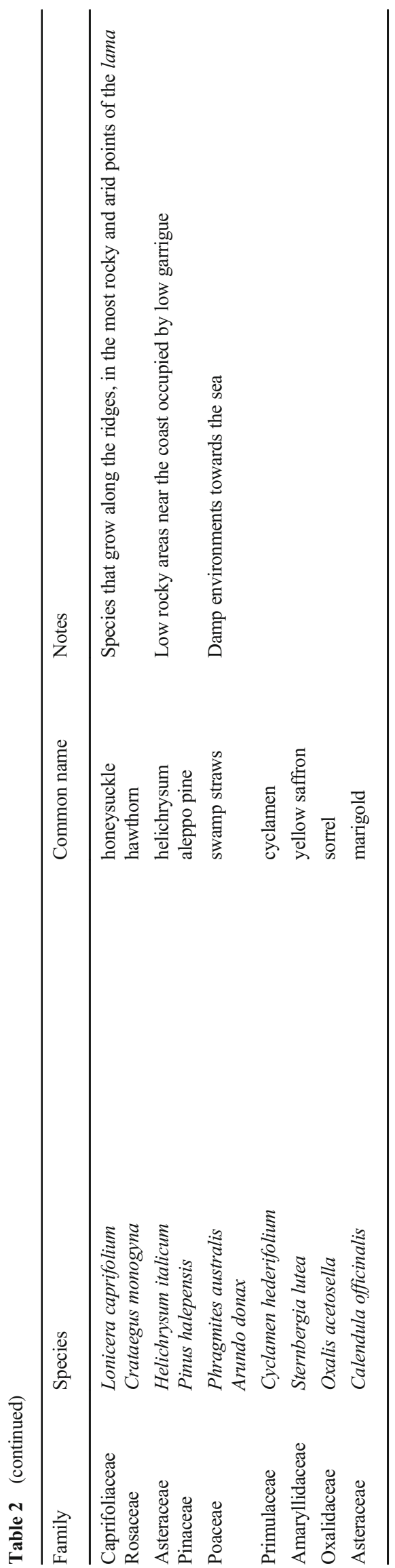

of Agenda 2030 through the enhancement of territorial resources and the identity of a place through the identification of local homeostasis and long-lasting balances with integration of the various territorial components: natural environment, built environment, anthropic environment (Nancy et al. 2000; Coetzee et al. 2014; Gray et al. 2016; Pressey et al. 2015). The various lama constitute important ecological and landscape systems, real ecological corridors, which cross the cities, offering the possibility of establishment of local homeostasis (ecological rebalancing) and hydrogeological protection of the urban fabric, protecting and safeguarding it. The characteristic flora and fauna of the lama represents a sort of recessed ecological corridor that crosses the cities and the countryside concerned. The presence of typical plant species (Mediterranean and sub-Mediterranean vegetation) and the presence of numerous animal species, performs many functions within the cities that are crossed by the lama. The vegetation and fauna of the lama contributes to the defense of nature by representing a mosaic of heterogeneous biotopes and to the defense of the landscape framework, framing elements worthy of observation, therefore increasing the attractiveness of the urban landscape (Tarsitano et al. 2017). The green areas of the lama, together with the other green spaces in the city, exert an influence on the urban climate, in particular on summer temperatures. The vegetation, through perspiration, subtracts a significant percentage of solar radiation by refreshing and humidifying the air, also constitutes a barrier to noise and pollution. The energy released in the city following combustion and other activities is mainly dissipated in the form of heat, to which is added the heat returned by the surfaces after the absorption of solar radiation during the day, therefore the urban climate is warmer and drier of the surrounding areas. The atmosphere overlooking the city heats up, resulting in the formation of upward currents which, rising, draw damp air from the surrounding areas creating a natural ventilation system, which helps to dilute the emissions of the central cores and refresh the atmosphere. The continuous green system is very advantageous, the creation of a real ecological network that crosses the city and connects with the countryside and the lama, thus constituting a set of ventilation corridors (Tarsitano et al. 2017).

In addition to ecological functions, green areas perform social functions because they represent a moment of recreation and because they constitute an experience of a cultural nature, given the possibility of acquiring botanical and faunal knowledge through it, which allow the spread of an environmental awareness at citizens and the rediscovery of a historical and cultural identity. In addition to combating the loss of both animal and plant biodiversity, the lama also take on a key role as a wildlife corridor for the movement of animal habitats and as buffer zones through stepping stones (point connection cores), both linear and corded and mosaic, also in the management and control of the synanthropic fauna coming from the cities, having functional characteristics such as to allow the species to move between the different cores by crossing a 


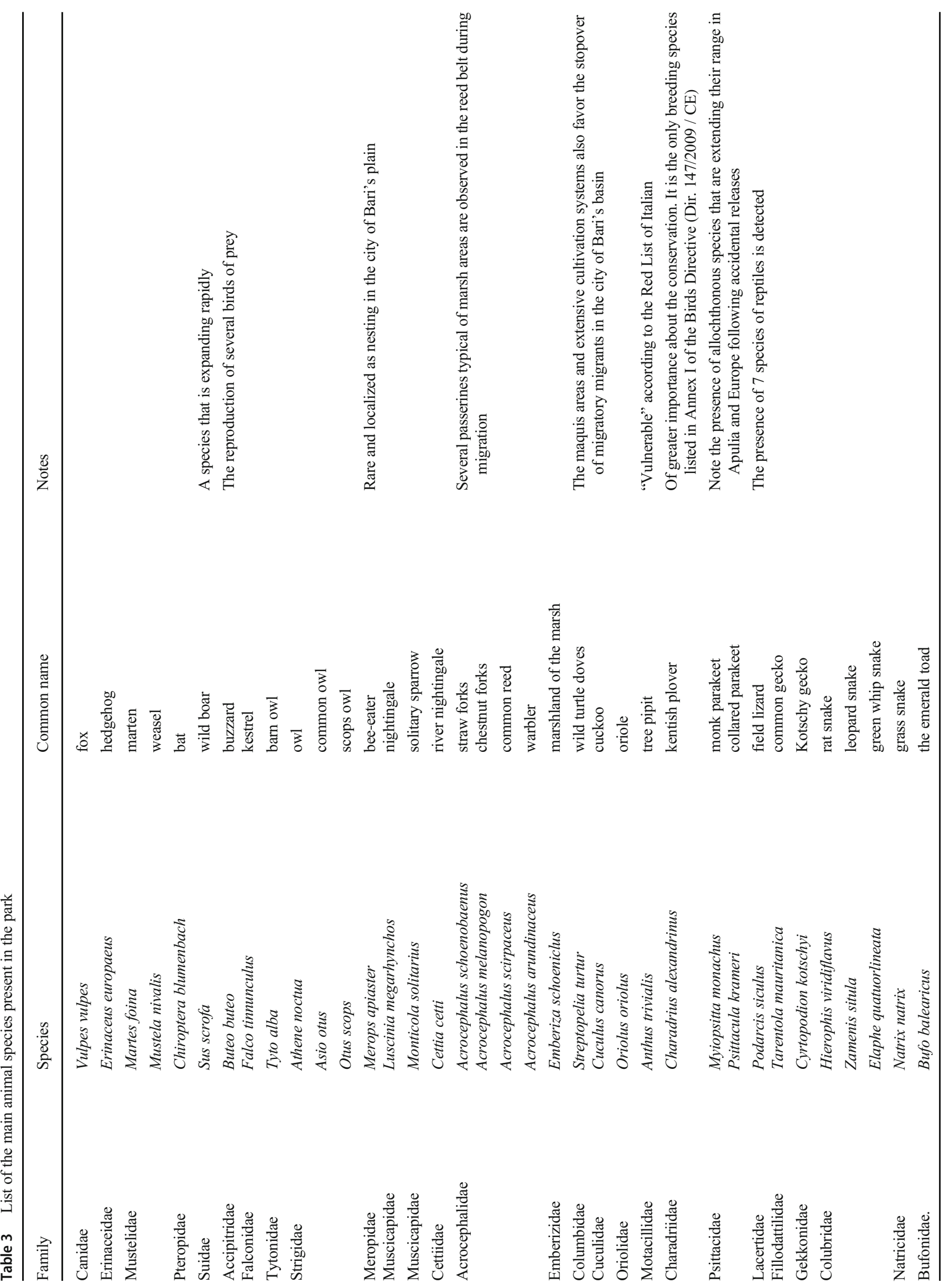


territorial matrix (degraded urban area) of environments not very suitable for their permanence (Barnes et al.,)

The objective must therefore be to promote the protection, enhancement and optimal allocation of territorial-environmental resources and therefore any action that degrades, defiles or eliminates these resources, intended as single entities or as complex balances. Economic development must be compatible with the carrying capacity of the planet's ecosystems and harmonious with the objectives of a democratic, just, equitable and supportive society. The protection of the historical and cultural identity, the safeguarding of the quality of the landscape system, of its environmental components and of its social and productive use, in the context of the principle of lasting and less unsustainable development, were results that could be pursued for sustainable development (Svancara et al. 2005). Therefore, a strategic vision for the Lama Balice Park represents an opportunity for social, environmental and cultural "redemption" for the entire metropolitan area of Bari. By definition, position and historical-landscape and environmental value, the Park is undoubtedly a "catalyzing" territorial element for urban suburbs and city centers, intended to welcome and encourage biological processes and vital relationships between living beings (Eklund and Cabeza 2017; Barnes et al. 2017; Leverington et al. 2010).

As the Strategic Document of the plan deals with, the Lama Balice Park is a meeting place, where everyone can experience new growth experiences in collective social life; it is a "dynamic" space, that is capable of changing its contents in relation to the social and economic logics that are put in place. The need to define the sense of place and local identity obliges "territorial operators" to interpret the processes and times of nature, society and related transformations and to contextualize their work, in order to guide the transformation towards virtuous processes.

The complexity of Lama Balice Park, made up of ecological, infrastructural, settlement and agricultural networks, leads us to reflect on the need to integrate these networks: the objective of protecting and improving existing biodiversity is associated with ensuring accessibility and usability for all (people with disabilities or not, children and elders, residents and foreigners), to facilitate recreational and educational activities with social and cultural purposes and to preserve the historical memory represented by the anthropic and natural landscape made of built elements, agricultural areas and vegetative elements of Lama Balice Park, a natural area of regional significance, is undoubtedly an area that must maintain constant dialogue with the context of urbanized areas present: both in the city of Bari and Bitonto territories, in fact, the Park becomes in some points "peri-urban" for the position so close to the city.

This aspect leads us to reflect on how to maintain dialogue without compromising the naturalness and biodiversity of the Park itself. Interventions, therefore, that enhance the historicity of the landscape, that protect 
biodiversity, that promote knowledge of the place and the active protection of citizens and association networks, which encourage social dynamism and the development of new forms of microeconomics based on a social and environmental ethics, are the best desirable for the management of the territory of Lama Balice Park.

Funding Open access funding provided by Università degli Studi di Bari Aldo Moro within the CRUI-CARE Agreement.

Open Access This article is licensed under a Creative Commons Attribution 4.0 International License, which permits use, sharing, adaptation, distribution and reproduction in any medium or format, as long as you give appropriate credit to the original author(s) and the source, provide a link to the Creative Commons licence, and indicate if changes were made. The images or other third party material in this article are included in the article's Creative Commons licence, unless indicated otherwise in a credit line to the material. If material is not included in the article's Creative Commons licence and your intended use is not permitted by statutory regulation or exceeds the permitted use, you will need to obtain permission directly from the copyright holder. To view a copy of this licence, visit http://creativecommons.org/licenses/by/4.0/.

\section{References}

AA.VV. Società Cooperativa Sociale Tracceverdi, Confederazione Italiana Agricoltori Puglia (2017) Un Parco da Vivere. Progetto sperimentale di rigenerazione ambientale e agricoltura sociale. Bari, Abap edizioni

Apulia Regional Territorial Landscape Plan - PPTR. Landscape areas (2015) https://www.paesaggiopuglia.it/pptr/ambiti-paesaggistici. $\mathrm{html}$

AsviS. Italy and the Sustainable Development Goals (2019) ASviS report 2019. Rome. Available online: https://asvis.it/rapporto-asvis-2019/

AsviS. Monitoring the SDGs at EU level with composite indicators (2018) ASviS report 2018. Rome. Available online: http://asvis.it/ public/asvis/files/ASVIS-REPORT-EU-COMPOSITES-FINAL. pdf

Barnes MD, Craigie ID, Dudley N, Hockings M (2017) Understanding local-scale drivers of biodiversity outcomes in terrestrial protected areas. Ann N Y Acad Sci 1399(1):42-60

Cagnetta G, Altini E, Clemente D, Labadessa R, Vovlas A (2019) New records and an updated checklist of the butterfly fauna (Lepidoptera: Papilionoidaea and Hesperioidea) of Puglia. XXI European Congress of Lepidopterology At University of Molise, Campobasso, Italy, South-eastern Italy. Conference paper

Coetzee BW, Gaston KJ, Chown SL (2014) Local scale comparisons of biodiversity as a test for global protected area ecological performance: a meta-analysis. PLoS one 27, 9(8):e105824

Conti F, Manzi A, Pedrotti V (1997) Liste Rosse Regionali delle Piante d'Italia. WWF Italia, Società Botanica Italiana, CIAS, Univ Camerino 139 pp.

Convention on Biological Diversity (2020) Zero draft of the post-2020 global biodiversity framework. Available online: https://www.cbd. int/article/2020-01-10-19-02-38

Dobson A (2007) Environmental citizenship: towards sustainable development. Sustain Dev 15:276-285

Eklund J, Cabeza M (2017) Quality of governance and effectiveness of protected areas: crucial concepts for conservation planning. Ann N Y Acad Sci 1399(1):27-41
Ferrara G (2017) Carta delle vocazioni faunistiche della città metropolitana di Bari. Bari (2017)

Ferraro PJ, Hanauer MM (2014) Advances in measuring the environmental and social impacts of environmental programs. Annu Rev Environ Resour 39:495-517

Giannoccaro R, Tracceverdi SCS, Puglia CIA (2017) Un Parco da Vivere. Progetto sperimentale di rigenerazione ambientale e agricoltura sociale. Bari, Abap ed 3:26-36

Gray CL, Hill S, Newbold T, Lawrence N, Hudson L Börger, Contu S, Hoskins A J, Ferrier S, Purvis S, Scharlemann J PW (2016) Local biodiversity is higher inside than outside terrestrial protected areas worldwide. Nat Commun 7:12306

Ipbes Regional Assessment Report on Biodiversity and Ecosystem Services for Europe and Central Asia (2018). Available online: https://ipbes.net/assessment-reports/eca

Leverington F, Costa KL, Pavese H, Lisle A, Hockings M (2010) A global analysis of protected area management effectiveness. Environ Manag 46:685-698

Mastropasqua F (2013) The herpetofauna of the Lama Balice regional Natural Park (Bari - Bitonto, Apulia). Conference proceedings: Congresso nazionale della Societas Herpetologica Italica 1:158-162

McCool SF, Stankey G (2004) Indicators of sustainability: challenges and opportunities at the Interface of science and policy. Environ Manag 33:294-305

Nancy B, Grove JM, Pickett STA, Redman CL (2000) Integrated approach to long-term studies of urban ecological systems. BioScience 50:571-584

Pressey RL, Visconti P, Ferraro PJ (2015) Making parks make a difference: poor alignment of policy, planning and management with protected-area impact, and ways forward. Philos Trans R Soc Lond Ser B Biol Sci 5:370(1681)

PUG - General Urban Plan - Municipality of Bari. Preliminary Programmatic Document (2014) https://www.comune.bari.it/web/ edilizia-e-territorio/pug-piano-urbanistico-generale

Raimondi V, Curzi D, Bertoni D, Olper A (2013) Off-farm labour decision of Italian farm operators in Working Papers from Factor Markets, Centre for European Policy Studies

Regional Law N.15 of 5/06/2007 'Establishment the Regional Natural Park of Lama Balice (2007) http://www.regione.puglia.it/ documents/10192/7080327/L_15_05_06_2007.pdf

Sinibaldi P, Tarsitano E, Colao M (2017) Project report: Balice smart. Environment:1-23

Strategic Plan BA2015 of the Metropolitan area of Bari (2015) http:// www.sistema.puglia.it/portal/page/portal/SistemaPuglia/ CooperazioneIstituzionale1/Dettaglio?id=116

Svancara LK, Brannon R, Scott JM, Groves CR, Noss RF, Pressey RL (2005) Policy-driven versus evidence-based conservation: a review of political targets and biological needs. Bioscience 55:989-995

Tarsitano E (2003) [Urban Ecosystem]. In: [Urban Parasitology: Cities, animals and public health] (V. Puccini \& E. Tarsitano, eds). Il sole 24 ORE Edagricole, Bologna, Italy, 21-36

Tarsitano E (2006) Interaction between the environment and animals in urban settings: integrated and participatory planning. Environ Man 38:799-809

Tarsitano E, Colao M, Sinibaldi P (2017) Biodiversity in the urban park of Lama Balice between protection and enhancement: the BASE project. Journal of Biodiversity and Environmental Sciences 10(4): 174-186

Tarsitano E, Calvano G, Cavalcanti E (2019) The Mediterranean way a model to achieve the 2030 agenda sustainable development goals (SDGs). Journal of Sustainable Development 12(1):108

Territorial Plan of the Natural Regional Park of Lama Balice - Strategic Plan Document (2016) http://www.parcolamabalice.it/il-parco/ piano-territoriale-del-parco/ 
Territorial Thematic Urban Plan for Landscape - PUTT/ p. of Apulia (2014) https://www.comune.bari.it/web/edilizia-e-territorio/pugpiano-urbanistico-generale

United Nations Department of Economic and Social - Affairs (UNDESA)-Division for Sustainable Development Goals (DSDG) (2015) Transforming our World: The 2030 Agenda for Sustainable Development (pp.1-41). United Nations. Available online: https:// sustainabledevelopment.un.org/post2015/transformingourworld
Van Swaay C, Cuttelod A, Collins S, Maes D, López Munguira M, Šašić M, Settele J, Verovnik R, Verstrael T, Warren M, Wiemers M and Wynhof I (2010) European red list of butterfies luxembourg: publications office of the European union

Veech JA (2003) Incorporating socioeconomic factors into the analysis of biodiversity hotspots. Appl Geogr 23:73-88 